\title{
A Case Report on Radiologic Findings of Thyrolipomatosis: a Rare Fat Containing Lesion diffusely Infiltrating throughout the Thyroid Gland
}

\author{
Kumar $\mathbf{R}^{1}$, Bhargava $\mathrm{A}^{2}$, Jaiswal $\mathbf{G}^{3}$
}

${ }^{1}$ Ravinder Kumar, Associate Professor; ${ }^{2}$ Abhishek Bhargava,Third Year Postgraduate Student (Radiodiagnosis); ${ }^{3}$ Gagan Jaiswal, Third Year Postgraduate Student (Radiodiagnosis); Department of Radiodiagnosis, Geetanjali Medical College \& Hospital, Geetanjali University, Udaipur, India

\begin{abstract}
A 73-year-old male presented with rapidly enlarging midline neck swelling of two months duration. Respiratory discomfort during breathing and hoarseness of voice occurred since few days. Clinical diagnosis was multinodular goitre. Sonography showed diffusely enlarged thyroid gland with altered echotexture. Multiple nodular echogenic lesions were noted in both the lobes. Unenhanced Computed tomography of the thorax and neck revealed a mass with no distinct margins and predominantly fat attenuation in both lobes of the thyroid gland. Magnetic Resonance images of the neck confirmed the fatty nature of the mass. These imaging findings signalled towards diffuse presence of mature adipose tissue inside thyroid gland which defines thyrolipomatosis. A near total thyroidectomy was performed and histopathological studies confirmed thyrolipomatosis in the post-operative specimen.
\end{abstract}

\section{INTRODUCTION}

$\mathrm{N}$ ormally, adipose tissue is observed in the parathyroid, salivary glands, thymus, breasts and pancreas; however, it is unusual to detect adipose tissue in the thyroid gland ${ }^{1}$. Fat containing lesions of thyroid are very rare with only a few cases documented in the literature. Thyrolipomatosis being the rarest with 11 cases reported in world literature as the presence of mature adipose tissue in the parenchyma of the thyroid gland is extremely rare. Thyrolipomatosis is characterized by diffuse infiltration of adipose tissue in the thyroid gland ${ }^{2}$. We report a case of thyrolipomatosis in a 73 year old male with emphasis on imaging findings.

\section{CASE REPORT}

A 73 year old male presented with rapidly enlarging midline neck swelling of two months duration. Respiratory discomfort during breathing and hoarseness of voice occurred since few days. There was no history of palpitation, tremor or sweating. A physical examination

Address for correspondence

Dr. Ravinder Kumar

Associate Professor

Department of Radiodiagnosis

AG-1, Geetanjali Medical Campus

Manvakhera, Udaipur-313002, Rajasthan, India.

E-mail: kundu19@yahoo.co.in revealed pallor without icterus. A large midline neck swelling was found, which moved with deglutition. The swelling was more prominent on right side and soft in consistency. All routine haematological investigations and thyroid function tests showed normal results. Clinical diagnosis was multinodular goitre. Sonography showed diffusely enlarged thyroid gland with altered echotexture. Multiple nodular echogenic lesions were noted in both the lobes. Unenhanced Computed tomography (CT) of the thorax and neck revealed a mass with no distinct margins and predominantly fat attenuation in both lobes of the thyroid gland. The intralesion low density areas suggested fat density (- 60 to -70 Hounsfield units [HU]) with mass effect on trachea (Figure 1 and figure 2). No enlarged lymph nodes could be noted.

Magnetic Resonance (MR) images of the neck confirmed the fatty nature of the mass. Fast spin-echo T1-weighted MR image showed the lesion to be isointense with subcutaneous fat. These imaging findings signalled towards diffuse presence of mature adipose tissue inside thyroid gland which defines thyrolipomatosis. Also, skin biopsy was negative for amyloid deposition. A near total thyroidectomy was performed and histopathological studies confirmed thyrolipomatosis in the postoperative specimen. 


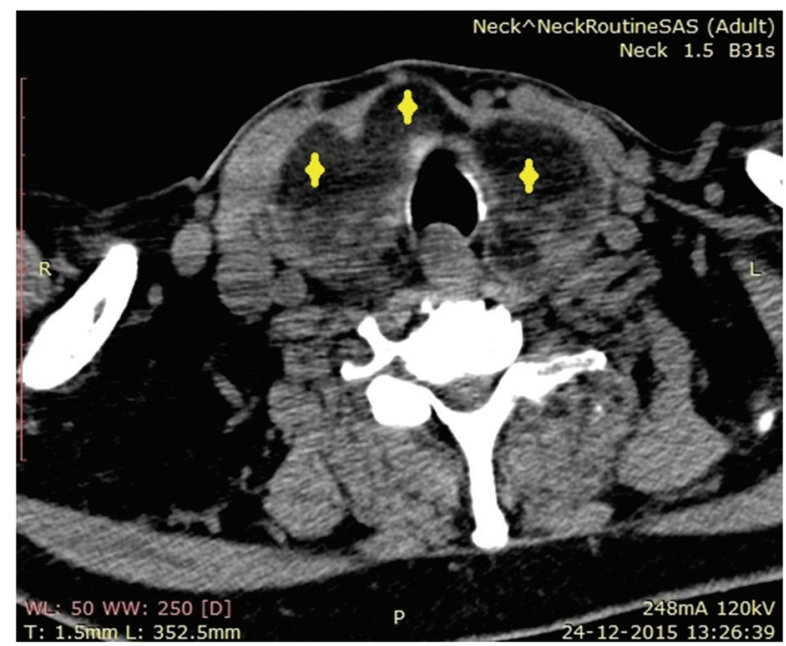

Figure 1: Unenhanced axial view CT scan shows diffuse, predominantly fatty mass $(-60 \mathrm{HU})$ with no distinct margins (marked by yellow asterisk) of the thyroid gland. The mass causes enlargement of the isthmus and extends to both right and left lobes. Small portions of the right and left lobes have a soft tissue attenuation (+50 HU), consistent with normal.

\section{DISCUSSION}

The origin of adipose tissue in the thyroid gland is unclear. Some authors consider these lesions to be developmental anomalies resulting from entrapment of adipose tissue in the thyroid gland during embryogenesis ${ }^{2-5}$. Schröder and Böcker stated that the adipose tissue was formed in response to tissue hypoxia, as result of stromal metaplasia or with the involution of senile fibroblasts ${ }^{6}$. Most of the fat containing lesions of thyroid are benign, occasionally malignant, hence rendering a correct diagnosis is essential'. Our patient had diffuse enlargement of the thyroid gland. His condition was euthyroid, and no enlarged lymph nodes or clinical signs of malignancy were found. Hoarseness of voice was due to pressure effect of enlarged thyroid on trachea. Diffuse enlargement of the thyroid gland could also be explained with amyloid goitre, but diffuse lipomatosis as seen in association with amyloid goitre is always associated with amyloid deposition elsewhere in the body. Skin biopsy of our patient did not disclose amyloid deposition. Thyrolipomas (adenolipomas) are

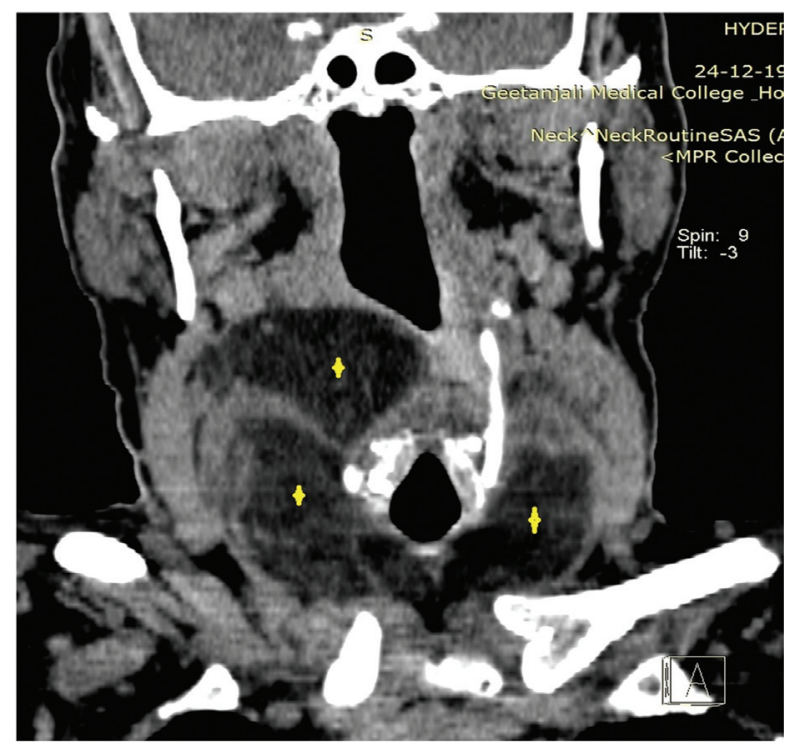

Figure 2: CT coronal reformated image showing regions of low density areas ( -60 to $-70 \mathrm{HU}$, marked by yellow asterisk) in both lobes\& isthmus of thyroid. Both thyroid lobes and isthmus are enlarged in size causing mass effect on trachea.

described as well-capsulated benign nodules containing fat and thyroid tissue but $\mathrm{CT}$ disclosed adiffuse mass with no distinct margins and predominantly fat attenuation in the thyroid gland ${ }^{8}$. Differential diagnosis of fat containing thyroid lesions include lymphocytic thyroiditis, parathyroid lipoma, heterotopic adipocytic nests, amyloid goiter, thyrolipoma, liposarcoma and encapsulated papillary carcinoma $a^{9,10}$.

\section{CONCLUSION}

Sonography is widely performed for imaging the thyroid gland and is usually sufficient to make a diagnosis when combined with laboratory findings and fine needle aspiration cytology ${ }^{2,4}$. Fatty tissue infiltration or fatty masses may be iso-echoic and cannot be differentiated from normal thyroid gland on ultrasonograms. For the current patient, sonography was not diagnostic, and the diagnosis of thyrolipomatosis was based on the CT and MR imaging appearances, and exclusion of other diseases. 


\section{REFERENCES}

1. Ge Y, Luna MA, Cowan DF, Truong LD, Ayala AG. Thyrolipoma and thyrolipomatosis: 5 case reports and historical review of the literature. Ann Diagn Pathol 2009;13:384-9.

2. Borges A, Catarino A. Case 53: adenolipoma of the thyroid gland. Radiology 2002;225:746-50.

3. Vaid S, Unune N, Shukla R, Kale K, Karnik S, Vaid N. Diffuse lipomatous infiltration of thyroid gland: $A$ rare cause of painless aymptomatic enlargement of the gland. Eur J Radiol 2010; 75(1):e9-e11.

4. Gupta A, Mathur SK, Batra C. Adenolipoma of the thyroid gland. Indian J Pathol Microbiol 2008; 51(4):521-2.

5. Daboin KP, Ochoa-Perez V, Luna MA. Adenolipomas of the head and neck: analysis of 6 cases. Ann Diagn Pathol 2006; 10(2):72-6.
6. Schröder S, Böcker W. Lipomatous lesions of the thyroid gland: a review. Appl Pathol 1985; 3(3): 1409.

7. Pradeep PV, Kumar R, Ragavan M, Ramakrishna BA. .Diffuse lipomatosis of thyroid with hyperthyroidism. J Postgrad Med 2010;56:35-6.

8. Kitagawa W, Kameyama K, Tamai S, Shimizu K, Ito $\mathrm{K}$, Akasu $\mathrm{H}$, et al. Adenolipoma of the thyroid gland: report of a case. Surg Today 2004; 34(7):593-6.

9. Breek JK, Vallaeys JH, Rutsaert RR. Simultaneous presentation of a thyrolipoma and a thymolipoma in a young man. Eur J Surg 1997;163:941-3.

10. LiVolsi VA. Surgical pathology of the thyroid. In: Bennington JL. eds. Major problems in pathology series. Philadelphia, PA: Saunders, 1990:323-50. 